\title{
The Holistic Age
}

\section{Dear Reader,}

The current period of engine development has long been called the emissions age, but since $1^{\text {st }}$ January 2016 we can justifiably talk of the holistic age.

IMO Tier III has been such a major landmark in the engine industry since 2008 that it was easy to forget that IMO's Energy Efficiency Design (EEDI) was introduced two years earlier. And, curcially, it is backed by the Ship Energy Efficiency Management Plan (SEEMP) which includes the incentives for retrofitting to improve the existing global fleet which are absent in the IMO emissions legislation.

The overall result is that, from the start of this year, new vessels must incorporate measures to reduce both noxious and greenhouse emissions and, importantly, the EEDI clearly points to a total systems approach. The vessel, not the engine is its focus, while the SEEMP encourages ship owners to adopt viable energy and emissions saving improvements over the lives of their assets.

This shift away from engine-centricity is timely. The quantum leaps in emissions and performance seen in the latest fourstroke engines are an exception that was preceded by - and will be succeeded by another phase of "business as usual" for engine developers. They will return to a painstaking search for improvements in the combination of fuel efficiency, emissions, power and load acceptance which parallels the ever smaller margins of improvement in Olympic sporting records.

For several years in all areas of engine application, the exclusive focus on the engine as the source of efficiency and emissions improvements sometimes led to the paradoxical situation of engine builders putting huge investments into low single digit percentage gains which might be immediately negated elsewhere in an overall power system by cost-cutting to offset the more expensive engines, or the choice of less expensive, less efficient propulsion elements.

Purely by chance, the combination of IMO Tier III and EEDI/SEEMP is timely with regard to the price of oil. Low oil prices have generally been a signal to ignore technologies such as waste heat recovery and turbo-compounding, which become borderline in terms of return on investment when energy is cheap.

Taking account of this new holistic phase, in this issue of MTZ industrial we are expanding our editorial coverage to include other parts of engine-driven power systems. Our first article in this new direction reports on the adoption of electric and hybrid drive systems in ships from the standpoint of a gear manufacturer.

Central to this holistic approach - indeed its major enabler - is electronic control of complete propulsion systems. And as we are seeing, the monitoring capabilities of on-engine electronics are now seen as a route to ever closer optimisation of complete systems.

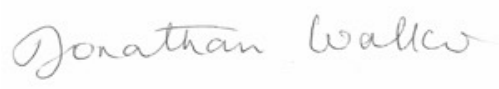

Jonathan Walker

Chief Correspondent, MTZindustrial

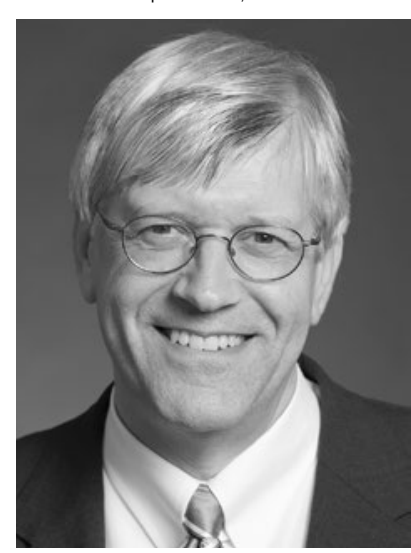

